\title{
The Laughter of Ticklishness Is a Darwinian Feature Related to Empathy in Both Genders: Self-Esteem in Men and Sexism in Women
}

\author{
Verónica Juárez-Ramos ${ }^{1 *}$, Elvira Salazar-López ${ }^{1}$, María Ángeles Rodríguez Artacho ${ }^{1}$, \\ K. Chmielowiec ${ }^{1}$, A. Riquelme ${ }^{1}$, J. Fernández-Gómez ${ }^{1}$, A. I. Fernández-Ramirez ${ }^{1}$, \\ A. Vicente de Haro ${ }^{1}$, A. Miranda ${ }^{1}$, M. Caballero ${ }^{1}$, B. Machado ${ }^{1}$, \\ Antonio González Hernández ${ }^{2}$, Emilio Gómez Milán ${ }^{1}$ \\ ${ }^{1}$ Departamento de Psicología Experimental, Universidad de Granada, Granada, Spain \\ ${ }^{2}$ Departamento de Psicología Social, Antropología Social, Trabajo Social y Servicios Sociales, \\ Universidad de Málaga, Málaga, Spain \\ Email: ${ }^{\text {juarezramosvero@hotmail.com }}$
}

Received November 19, 2013; revised December 19, 2013; accepted December 27, 2013

Copyright (C 2014 Verónica Juárez-Ramos et al. This is an open access article distributed under the Creative Commons Attribution License, which permits unrestricted use, distribution, and reproduction in any medium, provided the original work is properly cited. In accordance of the Creative Commons Attribution License all Copyrights (C) 2014 are reserved for SCIRP and the owner of the intellectual property Verónica Juárez-Ramos et al. All Copyright (C) 2014 are guarded by law and by SCIRP as a guardian.

\section{ABSTRACT}

The theory of false alarm for laughter could explain the involuntary laugh when someone is tickled. To put this hypothesis to the test, we handed out a questionnaire (180 items) with two hundred university students. Our main results are: In women who like being tickled, we discover components related to pleasure, erotism, feeling of affection, arousal, uncontrollability, domination, sexism and Darwinian (golden ratio) and psychological traits (empathy, low schizotypy and external locus of control) that are not present in the laughter at a stumble. The relation of both types of laughter with sense of humor is also differential. In men who like being tickled, we discover components related to masturbation, sexual fantasies, erotism, arousal, domination, sexist humour and Darwinian (square chin, feeling of masculinity) and psychological traits (empathic stress, low schizotypy, external locus of control and overall self-esteem). The relationship between being tickled and self-esteem shows a double aspect in men: It is positive in men who like being tickled and negative in men who do not like being tickled. For women there is not a relationship between self-esteem and tickling. Our conclusion is that laughter of ticklishness is a Darwinian feature related to empathy.

\section{KEYWORDS}

Tickling; Gender; Empathy; Self-Esteem; False Alarm

\section{Introduction}

The theory of the false alarm of laughter maintains that an involuntary laugh implies the evaporation of a threat; that is, we laugh to release tension after its activation by a danger that turned out not to be one [1]. Thus, we laugh when a clown falls over in the circus. In everyday life, we also laugh, in spite of ourselves, when someone trips up without major consequences. We are going to take the theory of false alarm and the involuntary laughter at a stumble as the reference in our investigation on the na-

${ }^{*}$ Corresponding author. ture of ticklishness. In tickling there is also laughter, but the investigation is not clear on whether the laughter from tickling is similar to that of the stumble without consequences [2]. With imagination, the false alarm in being tickled should produce an involuntary laugh on realising that no real threat exists, that it is a simulated attack, a game or, in a speculative interpretation characteristic of evolutionary psychology: what could be a harmful insect turns out to be the fingertips of your partner. However, in tickling, other ingredients appear to play a part: it has been affirmed that it has erotic value 
(feet tickling), that it forms part of the play between partners and of emotional dominance (it is easier for a grandfather to tickle his grandchild than the reverse). For this reason perhaps, heterosexual men do not tickle each other too much. Whatever the case, it seems that in this simulated struggle there is a winner (the one who tickles) and a loser (the one who is dying of unavoidable laughter). That is to say, a priori, we can differentiate three potential components in tickling: the false alarm, the seduction or sexual-erotic component and the domination or power motive. In any event, the question is whether the laughter from tickling and the laughter at another person's stumble, both involuntary, have something in common and if this common factor is the false alarm (a potential danger averted or that isn't one) and/or its hedonic value (does the false alarm produce physical or mental pleasure?).

Another of our aims in this study is to establish whether ticklishness is more a mental than a body trait, viceversa or both. For example, before we do mental arithmetic we count with fingers. But maybe physical flexibility doesn't correlate with cognitive flexibility: Does ticklishness belong to the world of laugh? Does it keep more relation to basic forms of laugh (as laughing for a stumble) or to more sophisticated ways (as irony)? If some of these hypotheses were true, the intensity of laughter from being tickled and the inability not to laugh when someone tripped would correlate. Does ticklishness depend on a person's physical or psychological traits? Is it more related to the Darwinian or the Popperian mind? [3]. Is it more related to biological traits, such as secondary sexual characteristics (as, for example, what happens with beauty ([4-6]) or to empathy and the theory of mind [7]-for example, empathy develops much earlier than mentalizing abilities?

\section{Method}

To put this hypothesis to the test, we handed out a questionnaire of 180 questions with two hundred university students aged between 18 and 45, of whom 110 were men and 90 women. The anonymity of the participants was preserved. The questions were combined randomly. All the questions had to be answered on a scale of 0 to 10 but without the option of responding with a 5. The key question was: 1) level of intensity of the laughter from being tickled.

The remaining questions make reference to:

A) The personality of the person who laughs when tickled. Also on Darwinian characteristics (secondary sexual characteristics);

B) The sense of humor;

C) Items related to the possible main components of ticklishness: sexuality, domination and false alarm most- ly.

We explain each section of the questionnaire in detail:

A-1) Personality traits (you are envious, fearful, a cry-baby, perfectionist, egocentric, ambitious, naïve, irresponsible, distrustful, level of self-esteem, level of selfconfidence, affectionate, nice, boring, level of energy, nostalgic, consistent, a procrastinator, intelligent, obsessive, shy, impulsive, happy, a liar, from 0 to 10 I'm the number...). Attempting to cover a large number of traits but focusing on those that have something to do with stimulation, fear and security, such as I'm fearful, I'm brave, I'm usually stimulated, security matters to me, I look for strong sensations, I like risk, danger attracts me... As we said each sentence was evaluated from zero to ten.

To complement this information, standardized questionnaires were run to our sample; questionnaires of empathy-the empathy scale TECA [8]; Schizotypy-the CAPE scale [9], locus of control-the locus of control questionnaire of [10], Self-esteem [11] and a questionnaire of sexism ([12]: Neosexism Scale). The aim is to determine whether ticklish people are more or less empathetic, schizotypal, with external locus of control, whether they are or not "macho" and their level of self-esteem compared to those who are not ticklish, complementing the rest of the information provided by the questionnaires.

A-2) A questionnaire of masculinity for men and a questionnaire of femininity for women based on the Darwinian characteristics. Asymmetry between the index and ring fingers were measured in men [13]. Then their secondary sexual characteristics were recorded from zero to ten by four trained judge observers: level of facial hair, square jaw, and arm and leg length, level of baldness, deep voice and muscular development. The average of masculinity calculated, just as their subjective assessment (from zero to ten) of how masculine they consider themselves and if they consider themselves as an alpha male. Women run a questionnaire of femininity. Their golden ratio was measured in different forms: Waist to hip ratio (WHR $=0.70) —[4]$; facial divine ratio like height of face divided by distance from eyes to mouth (=36\%); the canonical proportion (1:1.618) and breast, waist and hip direct measures (90:60:90 like reference)—we took these measures also for men. A visual analysis of their faces was also performed: full lips, small nose, big eyes, high cheekbones, facial symmetry. Each item is rated from zero to ten by four trained judge observers. The asymmetry between the index and ring fingers is also measured in women.

B) Questionnaire on types of humor, with explanation of the type of humor and examples: If I can't avoid laughing when someone stumbles (level of intensity of the laughter). Churches and priests jokes, sexist jokes 
(macho and feminist), black humor, white humor, sex jokes, political jokes and absurdities. Examples of irony and sarcasm. They value on a scale from zero to ten how much they like a type of humor or joke.

C-1) Sex life referred to different components of sexuality with the aim of determining if there is a sexual component in ticklishness, for example: ease of reaching orgasm, frequency of masturbation, level of sexual knowledge, frequency of daily thoughts about sex, frequency of sexual fantasies, frequency of intercourse, presence of sexual problems, importance of pleasure, I miss an ex, my current relationship is satisfactory, I don't forgive physical infidelity, I don't forgive emotional infidelity...

The questionnaire also included questions about the meaning of ticklishness: being tickled is erotic. It arouses me. Ticklishness involves emotional relationship with the other person. It is pleasant. Each item is valued on a scale from zero to ten.

C-2) Questions about domination and ticklishness, for example: "I like people of the opposite sex to tickle me", "I think that tickling has an element of domination", "I'm a sexist”, "I’m a xenophobic”, “I’m a racist”, “Tickling seems to me an act of violence", "I like people of the same sex to tickle me", "I like tickling people of the opposite sex", "I like tickling people of the same sex", "I don't like being tickled". "Being tickled bothers me”, "Ticklishness is uncontrollable", "I use to tickle people who are smaller or less burly than me", "I use to tickle people burlier than me”, "Ticklishness seems uncontrollable to me”, "I feel superior when I tickle”, "I feel inferior when I'm tickled”...

C-3) Questions concerning the response of the false alarm, such as: "I laugh when I get scared", "I laugh in uncomfortable situations", "I laugh when I make a mistake in front of other people”, "I have hysterical laughter quite often”, "I get scared easily”, "I laugh when I'm criticized”, "I laugh when I feel I dodged a hazard" (for example, "I almost stumble”), "I smile when someone is unfriendly with me”, "I startle easily”... Items are valued, as usual, on a scale from zero to ten.

\section{Results}

We analyzed every part of the questionnaire and the subtests contained therein. We did an analysis of correlations and declared significant all correlations with p value < 0.05. In pilot studies, we found that to obtain these associations, the intensity of ticklishness variable was more important than the body map of the ticklishness (where you are ticklish) and that there is an almost perfect correlation between the subjective intensity of ticklishness, the involuntary laugh at a stumble and the evaluation by judges of these two aspects. In order to prove it, we took ten people and tickled them with a feather and fingers, two independent judges evaluated the intensity of their laughter from the tickling (the correlation was $r=0.82$ and $r=0.73$, respectively). We did the same with another ten people and an independent judge evaluated the magnitude and duration of their laughter when watching videos showing people falling over (the correlation was $r$ $=0.78$ ).

Subsequently we observed that the pattern of correlations was completely different according to gender. That is, women and men show different relationships between these phenomena. The mean and typical deviations for the key question (ticklishness (T)) were for women: for $\mathrm{T}$, 6.77 (2.73). For men, the results were: for T, 4.09 (2.10). That is, there were significant gender differences in the intensity of the laughter from tickling, Cohen's (1988) delta being $=1.1$.

\subsection{Analysis for Women}

\subsubsection{Secondary Sexual Characteristics and Personality Traits}

The intensity of the ticklishness correlates with facial symmetry $(r=0.45)$ and with the average score on the questionnaire of Darwinian femininity $(r=0.56)$. As a curiosity, WHR correlates with the asymmetry index-ring fingers in women $(r=0.39)$ and waist size correlates with empathy total score $(r=0.49)$. Self-esteem correlated positively with breast size $(r=0.44)$ and with WHR $(r=0.42)$. For women, self-esteem correlated negatively with the depressive dimension of the CAPE ( $r=$ $-0.44)$.

For women ticklishness intensity correlated with schizotypy $(r=-0.41)$ in CAPE total. CAPE total score also correlated with the consideration that tickling is violence $(r=0.68)$. Tickling people of the same sex correlated with empathy ( $r=0.73$ ). Locus of control correlates with being good at tickling $(r=0.55)$.

However, the majority of correlations with ticklishness occur when the woman has traits like the following: with I am obedient $(r=0.40)$. Also when the subject has the traits: being responsible ( $r=0.42)$, being sensitive ( $r=$ $0.45)$ and falling in love easily $(r=0.44)$. Women also laugh when tickled when someone is nice to them ( $r=$ 0.38), in uncomfortable situations $(r=0.41)$ but not when they commit a fault $(r=-0.37)$. The intensity of laughter when tickled correlates with its uncontrollability $(r=0.70)$ and with being sexist $(r=0.49)$. Sexism correlates with tickling often $(r=0.88)$ and with being tickled often $(r=0.50)$ and it correlates negatively with "I don't like being tickled" ( $r=-0.47)$.

\subsubsection{Sense of Humor}

The correlation between ticklishness and laughter at a stumble was not significant $(r=0.17)$. Moreover, the common cases, where both occur in conjunction, appear to be due to a mediating variable, which is the item "I 
laugh easily at anything" that correlates with laughing at a stumble $(r=0.48)$ and laughter from tickling $(r=0.62)$. Other common factors are to laugh when scared ( $r=0.44$ and $r=0.53$ ) for ticklishness and laughing at a stumble respectively. For women, no other common factor exists between ticklishness and laughter at a stumble. To laugh at a stumble correlates with black humor in women $(r=$ $0.36)$, with hysterical laughter $(r=0.46)$ and with "I like cruel jokes” ( $r=0.44)$. Ticklish women are considered funny $(r=0.38)$.

For women, self-esteem correlates negatively with laugh when frightened ( $r=-0.36)$, with laugh at a stumble $(r=-0.38)$, with hysterical laughter $(r=-0.46)$ and with laugh at others' defects $(r=-0.44)$ and it correlates positively with being funny ( $r=0.52)$.

\subsubsection{Sexual Component}

If we analyse the specific correlations with ticklishness in women, the results show there is no correlation with ease of reaching orgasm $(r=-0.08)$ or other sexual variables but it exists a correlation with seeking pleasure $(r$ $=0.44)$. "I like the opposite sex to tickle me" correlates with "I think that tickling has an erotic component" ( $r=$ 0.48). "Tickling is linked to feelings of affection" correlates with "Being tickled arouses me" ( $r=0.51)$. "Tickling is erotic" with "Being tickled arouses me" $(r=0.64)$ and with "Tickling imply affection" $(r=0.58)$. The total score on empathy correlates with "Being tickled arouses me” ( $r=0.59)$, especially with empathic understanding $(r=0.59)$ and with empathic stress $(r=0.64)$. "I like men to tickle me" with "Tickling is affective" $(r=0.66)$. "I'm very ticklish" with "Tickling imply feelings" ( $r=$ 0.67), "Being tickled arouses me" ( $r=0.55)$, "I would never let a stranger tickle me" ( $r=0.47)$, "I laugh a lot when tickled" ( $r=0.52)$ and "Ticklishness is uncontrollable” ( $r=0.59)$. "Tickling involves feelings" with "I laugh a lot when tickled" ( $r=0.74)$ and with "Ticklishness is uncontrollable” $(r=0.72)$.

\subsubsection{Domination}

The correlations found are: "I don't like being tickled" with "I’m good tickling” ( $r=-0.46)$. "I'm very ticklish" with "Ticklishness is uncontrollable" $(r=0.52)$. "Tickling seems to me an act of violence" with locus of control ( $r=0.51)$ and $r=0.49$ with the subscale A of the depressive component of CAPE. "I laugh out loud when I'm tickled" with "Ticklishness is uncontrollable to me" $(r=0.65)$. "When I'm tickled I feel inferior" with the subscale A of the CAPE positive $(r=0.58)$. "When I tickle I feel superior" with "I'm very ticklish” ( $r=0.39)$. The total score on empathy correlate negatively with "I don't like being tickled" ( $r=-0.64)$ and "I feel inferior when tickled" ( $r=-0.57)$. "I'm more ticklish in my sole" with "I feel inferior when I'm tickled” $(r=0.50)$. "I like being tickled by people of the same sex" with "I feel superior when I tickle" ( $r=0.50)$ and with "Tickling is violent” ( $r=0.51)$. "I feel superior when I tickle" with "Tickling is violent” $(r=0.64)$ and "I'm good at tickling” with "I feel inferior when I'm tickled” ( $r=0.58)$.

\subsubsection{Discussion (on the Role of the False Alarm)}

To sum up, these two phenomena (ticklishness and laughter at a stumble) seem to be independent in women, except that they laugh at anything and that appears to be also a close relationship of both phenomenons with false alarm (laugh after being frightened).

With regard to ticklishness, pleasure and male domination are related in women who are responsible, sensitive, obedient, and who fall in love easily. Ticklishness correlate positively with the secondary sexual characteristics (breast size or WHR) and the secondary sexual characteristics correlate positively with self-esteem and empathy. Female ticklishness is above all related to sexism, high empathy, low schizotypy and external locus of control. Self-esteem doesn't seem to play a direct role in tickling.

With respect to involuntary laughter at a stumble, there does appear to be a clear relationship with false alarm: the taste for making cruel jokes, black humour and being strange... Highlight its negative correlations with selfesteem and empathy.

To summarise, in ticklishness (in women who like being tickled), we discover components related to pleasure, erotism, feeling of affection, arousal, uncontrollability, domination, sexism and Darwinian (golden ratio) and psychological traits (empathy) that are not present in the laughter at a stumble. The relation of both types of laughter with a sense of humor is also differential.

\subsection{Analysis for Men}

\subsubsection{Secondary Sexual Characteristics and Personality Traits}

Differentiating by gender, for men, Intensity of ticklishness correlates with total empathy $(r=0.33)$ and with empathic stress $(r=0.40)$. Locus of control correlates with being very ticklish $(r=0.64)$. "I'm tickled often" correlates with total CAPE $(r=-0.75)$. The correlation of the intensity of tickling with self-esteem $(r=0.35)$ was significant, as well as between ticklishness and feeling masculine (0.50) or feeling like an alpha male ( $r=$ $0.48)$ and with square chin $(r=0.41)$. Feeling masculine correlates with facial hair $(r=0.36)$, with muscular development $(r=0.56)$ with square chin $(r=0.44)$ and with average of male secondary sexual characteristics $(r$ $=0.41)$.

Tickling someone burlier correlates with empathy ( $r=$ $0.67)$ and self-esteem $(r=0.62)$. We also find correlation between self-esteem and masculinity $(r=0.49)$ and feel- 
ing like an alpha male $(r=0.60)$. Self-esteem correlates with negative $(r=-0.63)$ and depressive dimension $(r=$ -0.69) of CAPE and with total score on empathy ( $r=$ $0.77)$. The score in sexism correlates negatively with total empathy $(r=-0.68)$.

\subsubsection{Sense of Humor}

Ticklishness and involuntary laughter at a stumble don't correlate in men $(r=0.32)$.

Specific correlations for ticklishness and sense of humor are: with sexist humor ( $r=0.53)$, laugh at others' defects $(r=0.56)$, laugh to hurt $(r=0.76)$ and being happy $(r=0.52)$.

Regarding involuntary laughter at a stumble and sense of humor: Positive correlations specific to this involuntary laughter occur with hysterical laughter ( $r=0.47)$.

For men, self-esteem correlates as well with laughing out loud ( $r=0.62)$, laughing or saying something funny in uncomfortable or tense situations ( $r=0.57)$, smiling if someone is unfriendly with you $(r=0.57)$ and with being funny $(r=0.54)$.

\subsubsection{Sexuality}

Positive correlations specific to ticklishness are: masturbating a lot $(r=0.71)$ and having sexual fantasies $(r=$ 0.37). "I like to tickling the opposite sex" with "Being tickled arouses me" ( $r=0.69)$, "Tickling is erotic" ( $r=$ $0.78)$, "I'm good at tickling" ( $r=0.65)$, "I'm tickled often" $(r=0.61)$ and "Being tickled bothers me" $(r=$ $-0.71)$.

The negative correlations specific to involuntary laughter at a stumble occur with: level of energy ( $r=$ $-0.74)$ and thinking about sex $(r=-0.90)$.

\subsubsection{Domination}

For this variable, the main correlations found are: "I like to tickle the opposite sex" with "Tickling is violent" $(r=-0.66)$ and "I feel inferior when I'm tickled" $(r=$ -0.67). "I tickle burlier people" with "I feel inferior when I'm tickled" ( $r=0.68)$ and "I do not like Being tickled" with "I feel inferior" $(r=0.64)$. "I feel inferior when I'm tickled” with self-esteem $(r=-0.58)$. "Tickling is violent" with locus of control $(r=0.49)$.

\subsubsection{Discussion for Men}

To summarise, in ticklishness (in men who like being tickled), we discover components related to masturbation, sexual fantasies, erotism, arousal, domination, sexism humour and Darwinian (square chin, feeling of masculinity) and psychological traits (high empathy, low schizotypy, external locus of control and self-esteem). The relationship with self-esteem is double: positive with men who like being tickled and negative with men who do not like being tickled.

\section{Discussion}

With regard to the associations between involuntary laughter at a stumble and the laughter from tickling, in women they only occur in conjunction in those women who laugh at anything or laugh more after being frightened. The conclusion is that the laughter from tickling and the laughter at a stumble are not directly related. There could be women who laugh when tickled and do not laugh at a stumble and vice versa. In ticklishness we did find factors associated sense of humour, with hedonism and sexuality that are not present in the laughter at a stumble. To summarise, false alarm does not appear to provide a full explanation for these phenomena.

The specific traits of ticklishness in women are its relationship with pleasure and obedience. Ticklishness in men has a strong, specifically sexual (masturbation and fantasy) and hedonic (relationship with being happy) component and is associated with being masculine, with self-esteem. Ticklish men, it seems, are the men by whom women like to be tickled. Ticklish women are sensitive and fall in love easily; ticklish men not. The sexual component is in male ticklishness; female ticklishness is linked with love, arousal, affection and pleasure but not explicitly with sex. In ticklishness, men are not concerned about security and do not consider themselves boring. Ticklish women are fearful but they like risk, security and men who are sure of themselves, that is, they seek the pleasure of domination. Nevertheless, we must consider the differences between them according to personality traits and gender. Ticklishness appears to primarily reflect empathy and Darwinian femininity overall, as well as sexism in women and self-esteem in men (high if being tickled is pleasant and low if being tickled is unpleasant), sexual fantasies and subjective masculinity. In both genders, tickling is associated to empathy or ability to share emotions and sensations that develops much earlier than mentalizing abilities.

\section{Acknowledgements}

This study was supported by the research project PSI2009-11789/PSIC to Emilio Gómez Milán.

\section{Contributions}

Original idea Rodríguez Artacho and Gómez Milán. Text: Gómez Milán, Juarez Ramos, González-Hernández, Salazar-López. Data running and analysis: Chmielowiec, Riquelme, Fernández-Gómez, Fernández-Ramirez, Vicente de Haro, Miranda and Caballero.

\section{REFERENCES}

[1] V. S. Ramachandran and S. Blakeslee, "Phantoms in the Brain: Probing the Mysteries of the Human Mind,” Wil- 
liam Morrow \& Company, New York, 1998.

[2] M. Davila Ross, M. Owren and E. Zimmermann, "The Evolution of Laughter in Great Apes and Humans," Communicative and Integrative Biology, Vol. 3, No. 2, 2010, pp. 191-194. http://dx.doi.org/10.4161/cib.3.2.10944

[3] D. Dennett, “The Role of Language in Intelligence,” In: A. Burri, Ed., Sprache und Denken Language and Thought, W. de Gruyter, Berlin, 1987, pp. 42-55.

[4] S. M. Platek and D. Singh, "Optimal Waist to Hip Ratios in Women Activates Neural Rewards Center in Men," Plos One, Vol. 5, No. 2, 2010, p. e9042.

[5] C. Feng, "The Psychology and Biology of Beauty," Journal of Young Investigators, No. 6, 2002.

[6] M. J. Tovee and P. L. Cornelissen, "Is Beauty in the Eye of the Beholder?” Nature, Vol. 396, No. 6709, 1998, pp. 321-322. http://dx.doi.org/10.1038/24512

[7] T. Singer, "The Neuronal Basis and Ontogeny of Empathy and Mind Reading: Review of Literature and Implications for Future Research," Neuroscience and Biobehavioral Reviews, Vol. 30, No. 6, 2006, pp. 855-865. http://dx.doi.org/10.1016/j.neubiorev.2006.06.011

[8] B. López Pérez, I. Fernández Pinto and F. J. Abad, “TECA. Test de Empatía Cognitiva y Afectiva,” TEA
Ediciones, Madrid, 2008.

[9] N. C. Stefanis, M. Hanssen, N. K. Smirnis, D. A. Avramopoulos, I. Evdokimidis, C. N. Stefanis, et al., "Evidence That Three Dimensions of Psychosis Have a Distribution in the General Population," Psychological Medicine, Vol. 32, No. 2, 2002, pp. 347-358. http://dx.doi.org/10.1017/S0033291701005141

[10] J. B. Rotter, "Generalized Expectancies for Internal versus External Control of Reinforcement”, Psychologi- cal Monographs: General and Applied, Vol. 80, No. 1, 1966, pp. 1-28. http://dx.doi.org/10.1037/h0092976

[11] M. Rosenberg, "Society and the Adolescent Self-Image," Revised Edition, Wesleyan University Press, Middletown, 1989.

[12] B. Campbell, E. Schellenberg and C. Y. Senn, "Evaluating Measure of Contemporary Sexism," Psychology of Women Quarterly, Vol. 21, No. 1, 1997, pp. 89-102. http://dx.doi.org/10.1111/j.1471-6402.1997.tb00102.x

[13] A. A. Bailey and P. L. Huud, "Finger Length Ratio (2D: 4D) Correlates with Physical Aggression in Men But Not in Women,” Biological Psychology, Vol. 68, No. 3, 2005, pp. $215-222$.

http://dx.doi.org/10.1016/j.biopsycho.2004.05.001 